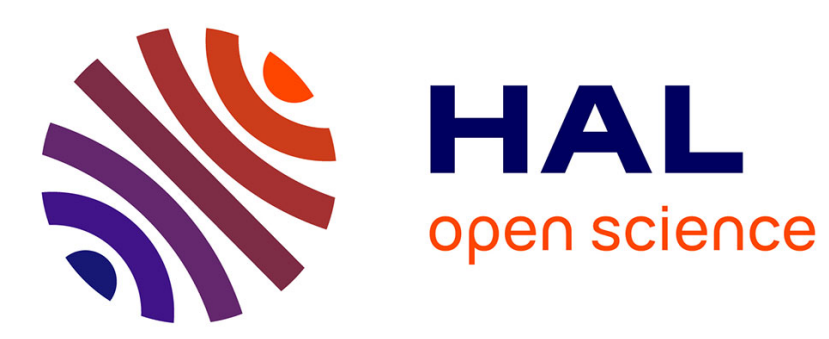

\title{
Translational and collective Diffusion in semi-dilute gels
}

E. Geissler, A.M. Hecht

\section{- To cite this version:}

E. Geissler, A.M. Hecht. Translational and collective Diffusion in semi-dilute gels. Journal de Physique Lettres, 1979, 40 (7), pp.173-176. 10.1051/jphyslet:01979004007017300 . jpa-00231600

\section{HAL Id: jpa-00231600 https://hal.science/jpa-00231600}

Submitted on 1 Jan 1979

HAL is a multi-disciplinary open access archive for the deposit and dissemination of scientific research documents, whether they are published or not. The documents may come from teaching and research institutions in France or abroad, or from public or private research centers.
L'archive ouverte pluridisciplinaire HAL, est destinée au dépôt et à la diffusion de documents scientifiques de niveau recherche, publiés ou non, émanant des établissements d'enseignement et de recherche français ou étrangers, des laboratoires publics ou privés. 


\title{
Translational and collective Diffusion in semi-dilute gels
}

\author{
E. Geissler \\ Laboratoire de Spectroscopie Optique, \\ Centre Universitaire de Savoie, B.P. 143, 73011 Chambéry Cedex, France
}

and A. M. Hecht

Laboratoire de Spectrométrie Physique $\left(^{*}\right)$,

Université Scientifique et Médicale de Grenoble, B.P. 53, 38041 Grenoble Cedex, France

(Reçu le 8 novembre 1978, révisé le 29 janvier 1979, accepté le 31 janvier 1979)

Résumé. - Les coefficients de diffusion translationnels et collectifs sont comparés dans des gels aqueux de polyacrylamide. Nous concluons que :

a) la viscosité du solvant ne dépend pas de la concentration du polymère ;

b) les mesures dynamiques de diffusion de lumière ne donnent les exposants des lois d'échelle qu'après avoir tenu compte de l'écoulement du solvant et des interactions hydrodynamiques résiduelles.
Abstract. - A comparison is made between measurements of the translational and collective diffusion constants in polyacrylamide-water gels. We conclude that :
a) the solvent viscosity does not depend on polymer concentration, and
b) scaling exponents can be deduced from dynamic light scattering measurements only after correction for solvent displacement and residual hydrodynamic interactions.

The properties of polymer solutions in the concentration range where the polymer molecules overlap (the semi-dilute regime) are described by a screening or correlation length $\xi[1,2]$. Using scaling arguments de Gennes [3] has shown that the static and dynamic behaviour of $\xi$ are the same, and in particular, in a good solvent $\xi^{-1}$ should vary as $c^{3 / 4}$, where $c$ is the weight of polymer dissolved in one cubic centimetre of solution. Neutron elastic scattering measurements of the concentration dependence of $\xi$ [1], as well as measurements of the longitudinal elastic modulus

$$
E \propto k_{\mathrm{B}} T / \xi^{3}
$$

(where $k_{\mathrm{B}}$ is Boltzmann's constant and $T$ the absolute temperature) by mechanical $[4,5]$ and inelastic light scattering methods [6] confirm that within experimental error this scaling relation is valid for the static case. In contrast, observations by inelastic light

$\left(^{*}\right)$ Laboratoire associé au C.N.R.S. scattering $[5,6,7]$ and, more recently, inelastic neutron scattering [8], of the collective motion diffusion constant

$$
D_{\mathrm{c}}=\frac{k_{\mathrm{B}} T}{6 \pi \eta \xi}
$$

(where $\eta$ is the solvent viscosity) yield exponents which are consistently smaller than 0.75 .

We have previously attempted to explain this discrepancy in terms of a concentration dependent solvent viscosity [6], presumably caused by the slowing of solvent molecular motions at an adsorbing surface $[9,10]$. Other authors call into question the equivalence between the dynamic and the static behaviour [11, 12], and connect the phenomenon with similar discrepancies in the dilute and the individual chain regimes $[13,14]$.

In this letter we describe measurements to compare the translational diffusion constant $D_{\mathrm{t}}$ of the solvent with the collective diffusion constant $D_{\mathrm{c}}$ in the same gel. If the solvent viscosity is affected by the presence 
of the polymer it should induce a corresponding change in the translational diffusion constant

$$
D_{\mathrm{t}}=\frac{k_{\mathrm{B}} T}{6 \pi \eta a}
$$

where $a$, the radius of the diffusing water molecule, may be expected not to depend on concentration. It is well known that $D_{t} / D_{0}$, where $D_{0}$ is the diffusion constant of the pure solvent, is concentration dependent $[15,16]$ as well as temperature dependent [17].

Firstly however, it should be mentioned that there is an important difference between translational and collective diffusion in a gel : in the former the solvent alone diffuses while the polymer remains, on average, stationary and there is therefore no relative displacement ; in the latter the motion of a polymer segment induces a counter-motion in the solvent, since the process occurs at constant volume :

$$
\varphi \dot{\mathbf{r}}+(1-\varphi) \mathbf{u}=0
$$

where $\varphi$ is the volume fraction of polymer, $\mathbf{r}$ the position of the polymer segment and $\mathbf{u}$ the solvent displacement velocity. The equation of motion of the polymer segment in the gel is [3]

$$
\Phi(\dot{\mathbf{r}}-\mathbf{u})=-E K^{2} \mathbf{r} .
$$

where $\Phi$ is the friction constant and $K$ the wavevector. Thus writing

$$
D_{\mathrm{c}}=\frac{E}{\Phi}
$$

one obtains an observed collective diffusion constant

$$
\begin{aligned}
D_{\mathrm{c}}^{\mathrm{obs}} & =D_{\mathrm{c}}(1-\varphi) \\
& =D_{\mathrm{c}}\left(1-\frac{c}{\rho_{\mathrm{p}}}\right)
\end{aligned}
$$

where $\rho_{\mathrm{p}}$ is the density of the polymer in the dissolved state and $D_{c}$ is as in eq. (2). Neglect of the factor $(1-\varphi)$ can cause a serious discrepancy in the apparent value of the scaling exponent for $D_{c}$. For example, for a polymer with $\rho_{\mathrm{p}}=1$ in a good solvent $\left(D_{\mathrm{c}} \propto c^{0.75}\right)$ the apparent collective diffusion constant in the range $0.01<c<0.1$ gives a reasonable approximation to a straight line in a log-log plot but has an average slope of about 0.71 .

In figure 1 are shown the measured values of $D_{t} / D_{0}$ for water in polyacrylamide gels as a function of polymer concentration at $300 \mathrm{~K}$. The gels were prepared at various concentrations as described in reference [6] and the measurements made with a nuclear spin echo technique [18] in the presence of a steady magnetic field gradient of about $0.5 \mathrm{G} / \mathrm{cm}$. The resonance frequency was $32 \mathrm{MHz}$. Because the observations were all made at long times $(>10 \mathrm{~ms})$ after the initial $\pi / 2$, pulse, the residual dipolar interactions between protons on the polymer chains cancel out

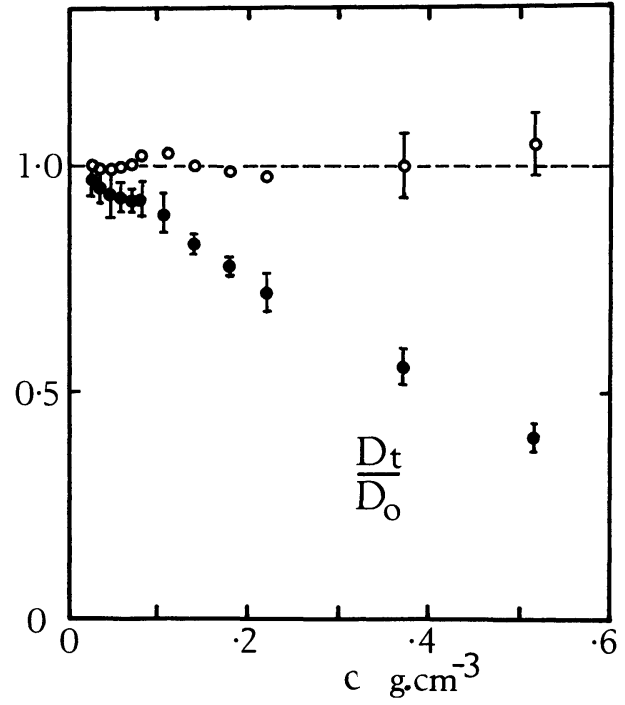

Fig. 1. - Relative translational diffusion constant $D_{\mathrm{t}} / D_{0}$ of water in polyacrylamide gels as a function of polymer concentration at $300 \mathrm{~K}$ (filled circles);

$$
\text { open circles : } \frac{D_{\mathrm{t}}}{D_{0}(1-1.6 \varphi)} \text {. }
$$

The measurements were made using pulsed magnetic resonance at $32 \mathrm{MHz}$ in a magnetic field gradient. The density $\rho_{\mathrm{p}}$ of polyacrylamide is taken as $1.345 \mathrm{~g} . \mathrm{cm}^{-3}$ in the relation $\varphi=c / \rho_{\mathrm{p}}$.

their contribution to the nuclear magnetic resonance signal, leaving only the signal from the protons of the diffusing water.

The experimental points of figure 1 fit a curve of the form

$$
\frac{D_{\mathrm{t}}}{D_{0}}=1-f \varphi
$$

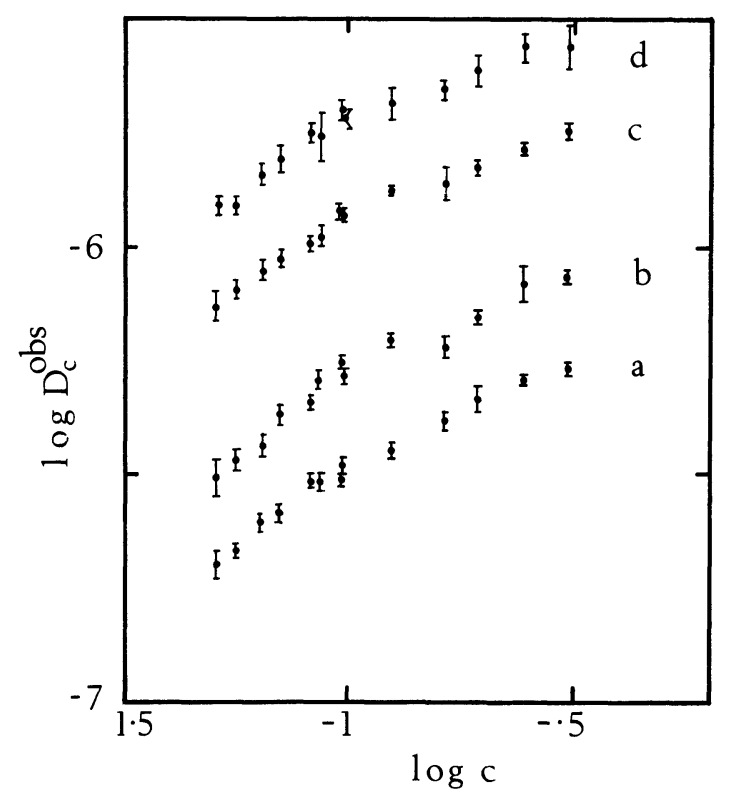

Fig. 2. - Logarithm of measured collective diffusion coefficient $D_{\mathrm{c}}^{\text {obs }}$ obtained by light scattering versus $\log c$, where $c$ is in $\mathrm{g} . \mathrm{cm}^{-3}$ and $D_{\mathrm{c}}^{\text {obs }}$ in $\mathrm{cm}^{2} . \mathrm{s}^{-1}$; a $284.5 \mathrm{~K}$; b $294.5 \mathrm{~K} ; \mathrm{c} 324 \mathrm{~K}$; d $351 \mathrm{~K}$. The error bars shown are standard deviations, each point being an average of four measurements. 
where $f$ is about 1.6 at this temperature (taking $\rho_{\mathrm{p}}=1.345$ for polyacrylamide). At lower temperatures the straight line becomes steeper, corresponding to larger $f$ values. If the observed variation of $D_{\mathrm{t}} / D_{0}$ were solely the result of a change in solvent viscosity, the total correction factor to be applied to the collective diffusion coefficient (eq. (2)) would become

$$
(1-\varphi)(1-f \varphi) \simeq 1-(1+f) \varphi .
$$

Figure 2 shows the experimental values of $\log D_{c}^{\text {obs }}$ versus $\log c$ for four different temperatures, each set of data displaying marked departure from linearity (negative curvature). If however the correction factor 9 is applied to these data, with $f \simeq 1.6$, positive curvature is generated. Acceptable linearity is obtained in the whole concentration range with a total correction factor $(1-\alpha \varphi)$ only if $\alpha$ lies close to 1.7 . The values of $D_{\mathrm{c}}^{\mathrm{obs}} /(1-\alpha \varphi)$ with $\alpha=1.67$ are shown in figure 3 in a double logarithmic representation.

Comparison of expression (9) with $D_{\mathrm{t}}$ and $D_{\mathrm{c}}^{\text {obs }}$ shows that these results are not compatible with a solvent viscosity varying more strongly than by a factor $(1-0.67 \varphi)^{-1}$. A more severe limit may be placed on the possible viscosity variation by compar-

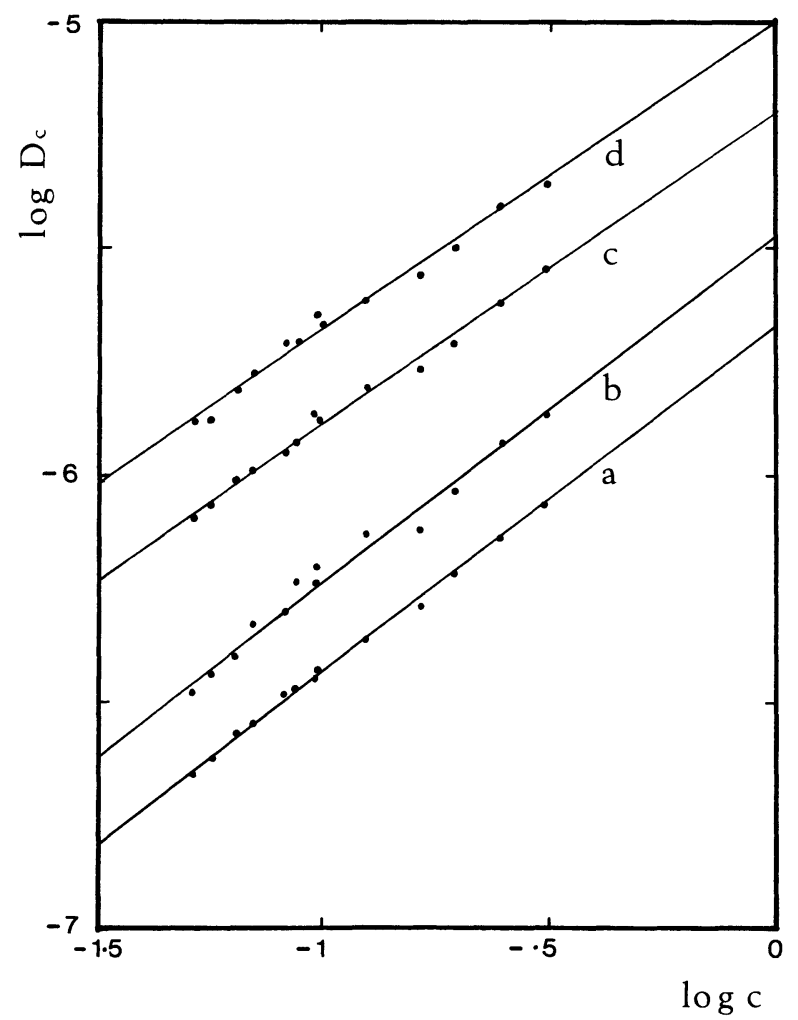

Fig. 3. - Logarithm of $D_{\mathrm{c}}=D_{\mathrm{c}}^{\mathrm{obs}} /(1-1.67 \varphi)\left(\mathrm{cm}^{2} \cdot \mathrm{s}^{-1}\right) v s$. $\log c\left(\mathrm{~g} . \mathrm{cm}^{-3}\right)$ at four temperatures. The straight lines shown are the least square fits to all the data points at each temperature.
a $284.5 \mathrm{~K} \quad \log D_{\mathrm{c}}=-5.676+0.75 \log c$
b $294.5 \mathrm{~K} \quad \log D_{\mathrm{c}}=-5.475+0.755 \log c$
c $324 \mathrm{~K} \quad \log D_{\mathrm{c}}=-5.200+0.685 \log c$
d $351 \mathrm{~K} \quad \log D_{\mathrm{c}}=-5.007+0.666 \log c$.

ing the dependence of $D_{t}(c)$ with the calculations of Wang [15] for an analogous case, self-diffusion of a liquid in the presence of large slowly moving obstacles : unscreened hydrodynamic interactions give rise to a reduction factor $\left(1-f^{\prime} \varphi\right)$ for the diffusion coefficient, where $f^{\prime}$, which depends on the geometry, has a minimum value of 1.5. Application of this result to the present case limits the possible fractional change in viscosity to about $\varphi / 10$.

Our conclusions are as follows :

1. The observed variation of $D_{t} / D_{0}$ is not caused by concentration dependence of the solvent viscosity, and is therefore hydrodynamic in origin. The observed variation at $300 \mathrm{~K}$ is in reasonable agreement with the calculations of Wang [15].

2. The presence of the solvent displacement factor $(1-\varphi)$ in light scattering measurements makes it necessary to work with very low polymer concentrations, and hence large molecular weights, in order to obtain dynamic scaling exponents in the semi-dilute regime that are comparable with the theory of de Gennes.

However, the factor $(1-\varphi)$ alone is not sufficient in the present case to account for all of the observed deviation of $D_{\mathrm{c}}^{\text {obs }}$ from linearity in a double logarithmic plot. The data suggest a total correction factor $(1-\alpha \varphi)$ with $\alpha \simeq 1.67$. This residual difference may come from incomplete screening of the backflow interactions [3], and would therefore be expected to vanish at high polymer concentrations.

It should be remarked that similar considerations apply also to the high frequency individual chain modes. As the hydrodynamic interactions are less screened at high wave vectors, dynamic scaling exponents will be affected.

3. The slopes of the straight line fits of $\log$ $D_{\text {c }}^{\text {obs }} /(1-\alpha \varphi) v s . \log c$ shown in figure 3 , with $\alpha=1.67$ are

$\begin{array}{lc}T \text { K } & \text { Slope } \\ - & - \\ 284.5 & 0.751 \pm 0.013 \\ 294.5 & 0.755 \pm 0.035 \\ 324 & 0.685 \pm 0.019 \\ 351 & 0.666 \pm 0.026\end{array}$

While the slopes corresponding to the lower temperatures are in reasonable agreement with the expected exponent 0.75 , there is a significant departure at the two higher temperatures. We cannot exclude the possibility of appreciable ionization of the water [19] or polyelectrolyte-like behaviour [20] at elevated temperatures due to partial hydrolysis of the acrylamide. To avoid this complication it would clearly be desirable to make similar observations in a non-polar system. 
Acknowledgments. - We would particularly like to thank M. Adam and L. Léger for helpful conversations, and J. P. Cohen Addad for making available the NMR apparatus. We are also grateful to the referees for their valuable contribution.

\section{References}

[1] Daoud, M., Cotton, J. P., Farnoux, B., Jannink, G., Sarma, G., Benoit, H., Duplessix, R., Picot, C. and DE GenNes, P. G., Macromolecules 8 (1975) 804.

[2] Daoud, M. and Jannink, G., J. Physique 37 (1976) 973.

[3] De Gennes, P. G., Macromolecules 9 (1976) 587 and 594.

[4] Bel Kebir-Mrani, A., Thesis, Strasbourg (1976).

[5] Munch, J. P., Candau, S., Herz, J. and Hild, G., J. Physique 38 (1977) 971.

[6] Hecht, A. M. and Geissler, E., J. Physique 39 (1978) 631.

[7] Adam, M., Delsanti, M. and Jannink, G., J. Physique Lett. 37 (1976) L-53.

[8] Richter, D., Hayter, J. B., Mezei, F. and Ewen, B., Phys. Rev. Lett. 41 (1978) 1484.

[9] Zimmerman, J. R. and Brittin, W. E., J. Phys. Chem. 61 (1957) 1328

[10] Woessner, D. E. and Zmmerman, J. R., J. Phys. Chem. 67 (1963) 1590
[11] Jasnow, D. and Moore, M. A., J. Physique Lett. 38 (1977) L-467.

[12] Daoud, M. and Jannink, G., J. Physique 39 (1978) 331.

[13] Adam, M. and Delsanti, M., Macromolecules 10 (1977) 1229.

[14] Munch, J. P., Lemaréchal, P., Candau, S. and Herz, J., J. Physique 38 (1977) 1499.

[15] Wang, J. H., J. Amer. Chem. Soc. 76 (1954) 4755.

[16] Derbyshire, W. and Duff, I. D., Faraday Discuss. Chem. Soc. 57 (1974) 243.

[17] VoGIN, R., Thèse de troisième Cycle, Grenoble (1974).

[18] Abragam, A., The Principles of Nuclear Magnetism (Oxford University Press) 1961, Ch. 8.

[19] Wang, J. H., J. Phys. Chem. 58 (1954) 686.

[20] De Gennes, P. G., Pincus, P., Velasco, R. M. and Brochard, F., J. Physique 37 (1976) 1461. 